\title{
International Biomedical Research and Research Ethics Training in Developing Countries
}

\author{
Fawaz Mzayek ${ }^{1 *}$ and David Resnik ${ }^{2}$
}

${ }^{1}$ Assisstant professor, University of Memphis, Memphis, USA

${ }^{2}$ Chair, National Institute of Environmental Health Sciences Institutional Review Board, National Institutes of Health, NC 27709, USA

\begin{abstract}
Developing an ethical framework for international biomedical research that is receptive to different cultural norms and moral values requires continuous and earnest dialogue between scientists from developed and developing countries. Adequate and sustainable training programs in biomedical research ethics for scientists from developing countries are essential to prepare competent partners from developing countries in this dialogue.
\end{abstract}

\section{Background}

In recent years, international research collaborations have been growing rapidly. Multinational pharmaceutical companies and academic institutions have expanded their research to developing countries. This in part is driven by the increased awareness of health as a global issue, the challenges imposed by new and resurgent global epidemics, the increased demand for new treatments, and practical and financial considerations of the pharmaceutical industry $[1,2]$. For example, a sharp increase in research in developing countries is largely due to the global HIV/AIDS epidemic and increased efforts to control malaria epidemic $[3,4]$. In addition, institutions within developing countries are increasingly engaged in biomedical research in order to map local health problems and allocate limited resources to remedy those problems. However, this research is often poorly regulated and does not meet widely accepted ethical standards $[5,6]$.

The globalization of biomedical research - purportedly guided by ethical principles established in developed countries - has led to numerous controversies and ethical dilemmas [7]. For example, the use of placebo controls in clinical trials for preventing perinatal HIV transmission provoked an intense debate concerning issues of research design, exploitation and fairness, and the relationship between a clinical investigator and a human subject [7-9]. This debate involved not only procedural and regulatory questions, such as those related to implementing research protocols or documenting consent, but also deeper questions concerning the social, cultural, and philosophical foundations of research.

Many controversies concerning the ethics of research in developing countries stem from differences in cultural and social norms, health priorities and policies, and wealth disparities between developed and developing countries. For example, informed consent to participate in research depends strongly on the principle of individual choice and autonomy that is deeply entrenched in western culture and philosophy, but is not a central value in many nonwestern societies $[7,10,11]$. Consequently, in developed countries, the individual decides whether to participate in research, and that process is documented by signing an informed consent form. However, neither the concept (individual decision-making) nor the procedure (signing a written document) is universally appropriate in traditional societies. In many traditional societies in developing countries some form of family or community consent must be obtained before consent is sought from potential subjects $[12,13]$. In other words, while community involvement in decision-making may be seen as an infringement of the rights of affluent, well informed individuals living in developed countries, it can be viewed as a layer of protection by poor and illiterate individuals living in developing countries
$[14,15]$. This culturally-based dissociation between group-centered decision-making in traditional communities and the emphasis on the autonomous individual in Western guidelines of informed consent process has greatly complicated the implementation of the informed consent principle in the realities of international research $[16,17]$. Researchers quickly discovered the urgent need to reconstruct the standards of informed consent in a flexible framework that is more accommodating to cultural diversities $[16,18]$.

Likewise, these difficulties in applying Western guidelines to biomedical research in developing countries are also relevant to other aspects biomedical ethics, including the principles of beneficence and justice [19].

\section{Ethical Relativism, Ethical Universalism and Ethical Pluralism}

Anthropological studies suggest that there are deep and widespread moral disagreements across different societies [20]. Practices and actions that are regarded as morally unacceptable by one society may be regarded as acceptable by another. Prominent examples include polygamy and arranged marriages. These observations have led some anthropologists and philosophers to conclude that all moral judgments are relative to a particular culture or society [20]. When applied to international biomedical research, this point of view implies that the ethics of a given study cannot be judged only by the standards developed in western cultures. This is because it is not possible to objectively determine the legitimacy of one culture's value system over that of another [21]. One consequence of this position is that ethical systems of host communities should have equal force to Western guidelines in governing the conduct of international research [21]. For example, if a non-western society requires that women participate in research only if they have spousal

*Corresponding author: Fawaz Mzayek, Assisstant professor, School of Public Health, Division of Epidemiology and Biostatistics, University of Memphis, Browning Hall 114, Memphis, TN 38152, USA, Tel: 9016781662; Fax: 9016781715; E-mail: fmzayek@memphis.edu

Received October 28, 2010; Accepted December 03, 2010; Published December 04, 2010

Citation: Mzayek F, Resnik D (2010) International Biomedical Research and Research Ethics Training in Developing Countries. J Clinic Res Bioeth 1:103. doi:10.4172/2155-9627.1000103

Copyright: ( 2010 Mzayek F, et al. This is an open-access article distributed unde the terms of the Creative Commons Attribution License, which permits unrestricted use, distribution, and reproduction in any medium, provided the original author and source are credited. 
approval, then westerners conducting research in that society should honor this practice. In fact, some commentators and political leaders have argued that insisting that research conducted in developing countries meet the ethical standards of developed countries is a form of moral imperialism [7,22]. Some authors even argue that insisting on seeking individual informed consent to participate in research in certain communities in developing countries, may weaken the social fabric of the society and introduce disorder in it with long-term consequences [23].

On the opposite side of the debate, some ethicists maintain that ethical standards are universal and must be applied no matter where the research is being performed [24]. Moreover, they argue that local laws and traditions cannot justify abandoning those universal principles [25].

Both the relativist and the Universalist point of view are problematic when applied to trans-cultural biomedical research. The former does not provide adequate ethical guidance to conduct research as it does not specify a mechanism to evaluate conflicting cultural views, while the latter does not recognize the huge diversity of cultural norms and ethical expectations in different societies. A middle-ground solution is offered in the form of ethical pluralism, which addresses major problems of the universalist and the relativist positions by acknowledging the central role of local cultures in shaping ethical rules of a given society, and by providing a mechanism to solve ethical disagreements between visiting researchers and host communities through continuous dialogue, mutual evaluation and negotiation [21]. Under the pluralistic approach, negotiated settlements of ethical conflicts provide_culturally-relevant guidelines to the specific research project at hand, instead of forcing rigid international ethical guidelines based on unrealistic assumptions of their universal applicability. This is very different from moral relativist approach in that although it recognizes and honors local traditions and practices, it involves a continuous critical appraisal of those values with a vision of a negotiated settlement when ethical conflicts arise. In addition, ethical pluralism contends that culture not only determines the content of the ethical system of a given community, but also its form [26]. That is, local culture determines how ethical values are expressed on the procedural level. This means that in some instances conflicting views may arise on implementation of an ethical principle even though there is no disagreement over the principle itself. For example, in some settings it is in appropriate to ask for signing a printed document after an oral consent has been provided by the potential participant [18]. Here, too, the pluralistic approach envisions negotiated solutions for means to implement ethical standards that are culturally-appropriate.

Therefore, and in order to conduct international biomedical research that is based on universally accepted ethical standards, and takes into account the great diversity in cultural values and social norms globally; we need to develop a trans-cultural ethical framework that is more receptive to variable ethical views of different societies. This framework can serve as general reference for international biomedical research, but which also includes detailed and specific guidelines on how to resolve ethical disagreements based on continuous negotiations and dialogue among the concerned parties: visiting researchers, local scientists and representatives from the host community [27].

\section{Towards A Trans-cultural Ethical Framework for Biomedical Research}

From this impassioned debate about the ethics of international research, two ideas have emerged that are notable for their relevance and applicability: [1] the need for trans-cultural research ethics, and [2] negotiated or procedural pluralism $[21,27,28]$. The first notion implies that an ethical framework for biomedical research should take into account the differences in ethical values and social norms across different cultures $[29,30]$. The second notion builds on the first and recognizes that agreement on universal ethical principles need not constrain the means pursued in following them [31]. That is, different approaches and strategies may equally facilitate the achievement of a single ethical standard or goal [28]. Consequently, useful approaches to research can be reached through negotiations and dialogue between sponsoring agencies and visiting researchers, on one side, and scientists and representative from host communities on the other.

Importantly, the negotiation of ethical guidelines and procedures need not involve compromising established ethical norms in research. Coercion, for example, is never acceptable. Yet what constitutes coercion and what does not, in a particular study and setting, should not be rigidly defined in some office in the country of the sponsoring agency. Rather, it should be a negotiated agreement between sponsors and visiting researchers, and local researchers and host community leaders. Of relevance in this regard is Emanuel et al.'s call to move from principles to benchmarks [32]. They suggest 31 ethical benchmarks which provide a set of practical measures that constitutes an ethical framework for multinational biomedical research (Table 1). These benchmarks can be viewed as blueprints for a negotiation plan to achieve ethical goals in research among the interested parties. A setting-specific version can be developed along the general lines of these benchmarks and negotiated among the sponsors, visiting researchers, local scientists and representatives of the host community.

Fruitful negotiations, however, require trained and competent negotiators on both sides, but little attention is paid to the lack of adequate training and expertise in the area of research ethics of researchers and professionals in regulatory bodies in developing countries [6,33].

\section{The Need for Adequate and Sustainable Training Programs in Research Ethics for Scientists in Developing Countries}

As international research has evolved, researchers from developed countries have become increasingly dependent on colleagues in the host countries to overcome linguistic and cultural barriers and to help implement research protocols. This assistance does not involve simply a correct translation of study protocols or informed consent documents, but implementing these documents in a culturally and socially appropriate manner. Untrained local researchers, therefore, may jeopardize not only the scientific merit of the study (e.g., by incorrectly translating a questionnaire item), but also its ethical standards. Two possible scenarios might be anticipated in this regard; both are problematic. Because of the strong influence of their own culture and the lack of training in ethical principles of biomedical research, local researchers may unknowingly inject their own values into study protocol and procedures, therefore engaging in a kind of ethical relativism where local norms take precedence over universal ethical principles. Alternatively, local researchers may subscribe entirely to western ethical norms, thus leading to a study that is legally valid, but ethically inappropriate (e.g. asking an illiterate subject to sign an informed consent document that she 


\begin{tabular}{|c|c|}
\hline Principles & Benchmarks \\
\hline Collaborative partnership & $\begin{array}{l}\text { Develop partnerships with researchers, makers of health policies, and the community. Involve partners in sharing responsibilities } \\
\text { for determining the importance of health problem, assessing the value of research, planning, conducting, and overseeing research, } \\
\text { and integrating research into the health-care system. Respect the community's values, culture, traditions, and social practices. } \\
\text { Develop the capacity for researchers, makers of health policies, and the community to become full and equal partners in the } \\
\text { research enterprise. Ensure that recruited participants and communities receive benefits from the conduct and results of research. } \\
\text { Share fairly financial and other rewards of the research. }\end{array}$ \\
\hline Social value & $\begin{array}{l}\text { Specify the beneficiaries of the research-who. Assess the importance of the health problems being investigated and the prospective } \\
\text { value of the research for each of the beneficiaries-what. Enhance the value of the research for each of the beneficiaries through } \\
\text { dissemination of knowledge, product development, long-term research collaboration, and/or health system improvements. Prevent } \\
\text { supplanting the extant health system infrastructure and services. }\end{array}$ \\
\hline Scientific validity & $\begin{array}{l}\text { Ensure that the scientific design of the research realizes social value for the primary beneficiaries of the research. Ensure that the } \\
\text { scientific design realizes the scientific objectives while guaranteeing research participants the health-care interventions to which } \\
\text { they are entitled. Ensure that the research study is feasible within the social, political, and cultural context or with sustainable } \\
\text { improvements in the local health-care and physical infrastructure. }\end{array}$ \\
\hline Fair selection of study population & $\begin{array}{l}\text { Select the study population to ensure scientific validity of the research. Select the study population to minimize the risks of the research } \\
\text { and enhance other principles, especially collaborative partnership and social value. Identify and protect vulnerable populations. }\end{array}$ \\
\hline Favorable risk-benefit ratio & $\begin{array}{l}\text { Assess the potential risks and benefits of the research to the study population in the context of its health risks. Assess the risk- } \\
\text { benefit ratio by comparing the net risks of the research project with the potential benefits derived from collaborative partnership, } \\
\text { social value, and respect for study populations. }\end{array}$ \\
\hline Independent review & $\begin{array}{l}\text { Ensure public accountability through reviews mandated by laws and regulations. Ensure public accountability through transparency } \\
\text { and reviews by other international and nongovernmental bodies, as appropriate. Ensure independence and competence of the reviews. }\end{array}$ \\
\hline Informed consent & $\begin{array}{l}\text { Involve the community in establishing recruitment procedures and incentives. Disclose information in culturally and linguistically } \\
\text { appropriate formats. Implement supplementary community and familial consent procedures where culturally appropriate. Obtain } \\
\text { consent in culturally and linguistically appropriate formats. Ensure the freedom to refuse or withdraw. }\end{array}$ \\
\hline Respect for recruited participants & $\begin{array}{l}\text { Develop and implement procedures to protect the confidentiality of recruited and enrolled and study communities participants. Ensure } \\
\text { that participants know they can withdraw without penalty. Provide enrolled participants with information that arises in the course of the } \\
\text { research study. Monitor and develop interventions for medical conditions, including research-related injuries, for enrolled participants } \\
\text { at least as good as existing local norms. Inform participants and the study community of the results of the research. }\end{array}$ \\
\hline
\end{tabular}

Table 1: Ethical principles and benchmarks for multinational clinical research.

cannot read). In this case, local researchers may become complicit in an ethical imperialism of sorts, losing in the process their important role as ethical "negotiators" on behalf of their community [7]. As Benatar rightly notes: "The challenges here are to avoid both ethical imperialism and ethical relativism" [15].

Interestingly, the vast majority of the discussion on issues of international research has been driven, explicitly and implicitly, by the perceived need to educate the scientific and regulatory communities in developed countries on issues of cultural diversity, the need of nuanced thinking and negotiation, and different perceptions of the role and rights of the individual in different societies [15]. Much less discussion has been devoted to the inadequate training and expertise in the area of responsible conduct of research of researchers and other professionals in regulatory bodies in developing countries $[6,33]$. What seems to have been lost in this discussion is that in order to utilize the mechanisms for implementing trans-cultural research ethics, set under ethical pluralism approach, it is equally important that researchers from developing countries be trained in international ethical principles and regulations. To be able to engage in a mutual evaluation of the local and international ethical expectations from research, and to negotiate acceptable solutions for ethical disagreements, researchers and health professionals from developing countries need adequate and continuous training in international ethical principles, which have been developed through the years by many researchers, ethicists, philosophers and lawyers, and which continue to provide ethical frameworks and guidance for developed countries' institutions and for international organizations.

Such training programs should include not only theoretical knowledge about ethical rules in research, but also adequate training in research methodology, because studies with flawed design are unethical by their very nature. They should also include training in practical skills such as presenting cases, conducting protocol reviews, and leading group discussions. These applied skills will allow the trainees to become trainers of their peers, and will enable them to become highly-qualified members in local institutional review boards (IRB). This way, previously trained research ethicists from developing countries become an important factor for the sustainability of training programs.

In summary, as successful negotiations require competent negotiators on both sides, training scientists from developing countries in research ethics is instrumental for the development of trans-cultural ethical frameworks and negotiated ethical processes for international research collaborations. Such training programs should include instruction on ethical principles of biomedical research, research methodology, and applied experience activities. Investing in training researchers from developing countries in responsible conduct of biomedical research will serve many worthy objectives, including improving scientific and ethical standards of studies designed by local scientists, facilitating the adaptation of international research protocols and procedures to the local culture without jeopardizing their scientific and ethical integrity, and building public trust which is essential to support international biomedical research [34].

\section{References}

1. Global Health Initiative (2008) Why Global Health Matters.

2. Petryna A (2009) When Experiments Travel. Princeton University Press.

3. Greenwood B, Mutabingwa T (2002) Malaria in 2002. Nature 415: 670-672.

4. Emanuel EJ, Miller FG (2001) The ethics of placebo-controlled trials--a middle ground. N Engl J Med 345:915-919.

5. Hyder AA, Wali SA, Khan AN, Teoh NB, Kass NE, et al. (2004) Ethical review of health research: a perspective from developing country researchers. $J$ Med Ethics 30: 68-72

6. Singer PA, Benatar SR (2001) Beyond Helsinki: a vision for global health ethics BMJ 322: 747-748.

7. Resnik D (2006) Biomedical research in the developing world: Ethical issues and dilemmas. In: Iltis A, editor. Research Ethics.

8. Aaby P, Babiker A, Darbyshire J, Nunn A, Barreto S, et al. (1997) Ethics of HIV trials. Lancet 350: 1546.

9. Lurie P, Wolfe SM (1997) Unethical trials of interventions to reduce perinata transmission of the human immunodeficiency virus in developing countries. $\mathrm{N}$ Engl J Med 337: 853-856. 
Citation: Mzayek F, Resnik D (2010) International Biomedical Research and Research Ethics Training in Developing Countries. J Clinic Res Bioeth 1:103. doi:10.4172/2155-9627.1000103

Page 4 of 4

10. Tangwa GB (2000) The traditional African perception of a person. Some implications for bioethics. Hastings Cent Rep 30: 39-43.

11. Barrett RJ, Parker DB (2003) Rites of consent: negotiating research participation in diverse cultures. Monash Bioeth Rev 22: 9-26.

12. Benatar SR, Bhutta ZA, Daar AS, Hope T, MacRae S, et al. (2001) Clinical ethics revisited: responses. BMC Med Ethics 2:E2.

13. Krogstad D, Diop S, Diallo A, Mzayek F, Keating J, et al. (2010) Informed Consent in Developing and Developed Countries: the Rationale for Different Approaches. Am J Trop Med Hyg 83: 743-747.

14. Elliott AC (2001) Health Care Ethics: Cultural Relativity of Autonomy. J Transcult Nurs 12: 326-330.

15. Benatar SR (2002) Reflections and recommendations on research ethics in developing countries. Soc Sci Med 54: 1131-1141.

16. Crigger NJ, Holcomb L, Weiss J (2001) Fundamentalism, multiculturalism and problems of conducting research with populations in developing nations. Nurs Ethics 8: 459-468.

17. Shaibu S (2007) Ethical and cultural considerations in informed consent in Botswana. Nurs Ethics 14: 503-509.

18. Mystakidou K, Panagiotou I, Katsaragakis S, Tsilika E, Parpa E (2009) Ethical and practical challenges in implementing informed consent in HIVIAIDS clinical trials in developing or resource-limited countries. SAHARA J 6: 46-57.

19. Christakis NA (1988) The ethical design of an AIDS vaccine trial in Africa. Hastings Cent Rep 18: 31-37.

20. Gowan C (2008) "Moral Relativism", The Stanford Encyclopedia of Philosophy.

21. Christakis A (1996) The distinction between ethical pluralism and ethical relativism: Implications for the conduct of transcultural clinical research.
Research Ethics on Human Subjects: Facing the 21st Century. University Publishing Group 261-280

22. Mbidde E (1998) Bioethics and local circumstances. Science 279:155

23. Newton LH (1990) Ethical imperialism and informed consent. IRB 12:10-11.

24. Schoepf BG (1991) Ethical, methodological and political issues of AIDS research in Central Africa. Soc Sci Med 33: 749-763.

25. Angell M (1988) Ethical imperialism? Ethics in international collaborative clinical research. N Engl J Med 319: 1081-1083.

26. Christakis NA (1992) Ethics are local: Engaging cross-cultural variation in the ethics for clinical research. Soc Sci Med 35:1079-1091.

27. Konrad M. The Ethical Aspects of Biomedical Research in Developing Countries: Norms, Values and Trnas-Cultural Medical Ethics 2003.

28. Holms S. The Ethical Aspects of Biomedical Research in Developing Countries: Moral Pluralism. 2003.

29. Baker C (1997) Cultural relativism and cultural diversity: implications for nursing practice. ANS Adv Nurs Sci 20: 3-11.

30. Brannigan M (2000) Cultural diversity and the case against ethical relativism Health Care Anal 8: 321-327.

31. Resnik DB (1998) The ethics of HIV research in developing nations. Bioethics 12: $286-306$

32. Emanuel EJ, Wendler D, Killen J, Grady C (2004) What makes clinical research in developing countries ethical? The benchmarks of ethical research. J Infect Dis 189: 930-937.

33. Kirigia JM, Wambebe C, Baba-Moussa A (2005) Status of national research bioethics committees in the WHO African region. BMC Med Ethics 6: E10.

34. Resnik D (2007) What is Ethics in Research and why is it Important? 